\title{
An Integrated System for the Treatment of Coal Conversion Wastewaters
}

\author{
Final Technical Report
}

\author{
By \\ Henry Y. Wang \\ Keeran R. Srinivasan
}

Work Performed Under Contract No.: DE-FG22-91PC91295

For

U.S. Department of Energy

Office of Fossil Energy

Federal Energy Technology Center

P.O. Box 880

Morgantown, West Virginia 26507-0880

\author{
RECEVED \\ MAR 02.9929 \\ OSTI
}

By

Department of Chemical Engineering

University of Michigan

Ann Arbor, Michigan 48109-2136 


\section{Disclaimer}

This report was prepared as an account of work sponsored by an agency of the United States Government. Neither the United States Government nor any agency thereof, nor any of their employees, makes any warranty, express or implied, or assumes any legal liability or responsibility for the accuracy, completeness, or usefulness of any information, apparatus, product, or process disclosed, or represents that its use would not infringe privately owed rights. Reference herein to any specific commercial product, process, or service by trade name, trademark, manufacturer, or otherwise does not necessarily constitute or imply its endorsement, recommendation, or favoring by the United States Government or any agency thereof. The views and opinions of authors expressed herein do not necessarily state or reflect those of the United States Government or any agency thereof. 


\section{DISCLAIMER}

Portions of this document may be illegible in electronic image products. Images are produced from the best available original document. 
FINAL TECHNICAL REPORT
(Grant no. DE-FG22-91PC91295) -47

\title{
AN INTEGRATED SYSTEM FOR THE TREATMENT OF COAL CONVERSION WASTEWATERS:
}

\author{
Henry Y. Wang and Keeran R. Srinivasan \\ Department of Chemical Engineering \\ University of Michigan \\ Ann Arbor, Mich. 48109-2136.
}

Summary

Treatment of " mixed waste " from coal conversion wastewaters involves the degradation of toxic organics and the removal of heavy metals. An integrated and cost-effective treatment scheme that can implement such a process is considered essential to promote continued development and growth of coal conversion processes without any deleterious effects on our ecosystem. We have recently developed a pH-dependent, reversible heavy metal adsorption/desorption process which promises to be a cost-effective alternative to the treatment and disposal options currently in place for these inorganic contaminants. Our work shows that: (1). Polydisperse, industrial-grade surfactants can be used in the development of novel, surfactant-coated smectitic clays containing up to $50 \%$ by weight of adsorbed surfactant, (2). Reversible adsorption and desorption of cationic (Cu(II) and $\mathrm{Cd}(\mathrm{II}))$ and anionic ( $\mathrm{Cr}(\mathrm{VI})$ ) heavy metals from their respective aqueous solutions onto these these surfactant-modified smectites can be effected using pH of the medium as a " switch ", and (3). These surfactant-modified smectites can be repeatedly used (up to 5 times) with only a minimal loss in their adsorption potency and with very little leaching of the adsorbed surfactants.

\section{Research Results}

\section{A. Design of Surfactant Modified Clays:}

The use of surfactant-modified clays for the removal of toxic organics from wastewater streams has been extensively studied at The University of Michigan. Similarly, mineral oxides, dead and active algal cells have been shown to be effective in the uptake of cationic and anionic heavy metals. However, the development of a single adsorbent system that will be effective against the 
commonly-occurring "mixed" waste streams is still in its infancy. During the course of our joint research on novel wastewater treatment processes, we have prepared modified-smectites using an alkyl diamine surfactant of the type:

$$
\text { R-NH- }\left(\mathrm{CH}_{2}\right)_{3}-\mathrm{NH}_{2}
$$

as the active component in the sorption process. The diamine used extensively in our study is Duomeen-T (DT). It is a commercially available surfactant blend of greater than $98 \%$ purity. Duomeen-T (DT) is a water-insoluble, aliphatic diamine derived from alkyl substituted 1,3-diamino propane. The 1,3-diamino propane, consisting of a primary and a secondary amino group, is the head group of this asymmetric molecule and the alkyl chains are derived mainly from:

$\begin{array}{lll}\text { Octadecenyl } & \left(\mathrm{C} 18^{\prime}\right) & 37.0 \% \\ \text { Octadecyl } & (\mathrm{C} 18) & 23.0 \% \\ \text { Hexadecyl } & (\mathrm{C} 16) & 29.0 \% \\ \text { Tetradecyl } & (\mathrm{C} 14) & 4.0 \%\end{array}$

DT is an easily dissociable, bifunctional surfactant diamine and plays a pivotal role in the recovery of heavy metals (as shown below) and the alkyl group, $R$, provides the sorption sites for the partitioning of hydrophobic organic compounds (HOCs). The potentiometric titration of DT in 5\% isopropyl alcohol (IPA) -water mixture is shown in Fig.1. The titration data reveal that DT has a broad distribution of basicities with a mean pKa of 7.55. It appears that there is not a significant difference in the basicity between secondary and the primary amino groups on DT. The end point of the acid titration ( 2 moles $\mathrm{HCl} /$ moleDT) verifies the purity and the dibasicity of DT. The ratio of [Base]/[Acid] form of DT as a function of $\mathrm{pH}$ was calculated and this is also shown in Fig. 1. It can be seen that DT is more than $99 \%$ protonated below pH 5.0 and that a significant amount of the neutral form of DT exists between $\mathrm{pH} 7.5$ - 8.0. An understanding of the role of DT in heavy metal adsorption/desorption from aqueous solutions can be obtained on the basis of the $\mathrm{pH}$ titration of DT in IPA-water mixture in presence of 0.2 mmoles of $\mathrm{Cu}(\mathrm{II})$. The results are shown in Fig. 2.

In presence of $\mathrm{Cu}(\mathrm{II})$, an intense blue color develops in solution signaling the formation of a Lewis acid-base $\mathrm{Cu}$ (II)-DT complex at mildly alkaline $\mathrm{pH}$. During acid titration, the absorbance of $\mathrm{Cu}-\mathrm{DT}$ complex as a function of $\mathrm{pH}$ was measured at $626 \mathrm{~nm}$ and was ratioed against the highest value of absorbance obtained during titration. This is also shown in Fig. 2. The following chemical 
reactions are thought to occur in solution during the acid titration of DT in presence of $\mathrm{Cu}(\mathrm{II})$

Fig. 2 Titration of DT in Presence of $\mathrm{Cu}(\mathrm{II})$
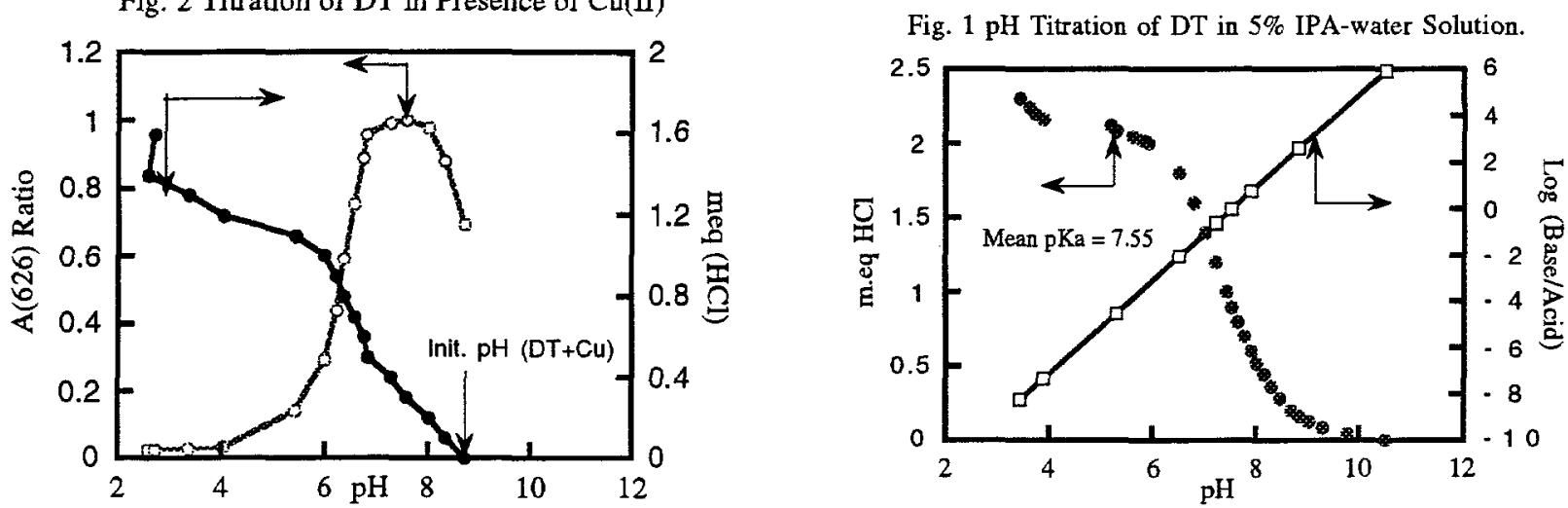

and will help explain the adsorption and desorption of cationic and anionic heavy metals as a function of solution $\mathrm{pH}$.

\begin{tabular}{|c|c|c|c|c|}
\hline (a) DT & $+2 \mathrm{H}_{2} \mathrm{O}$ & $=\left[\mathrm{DTH}_{2}\right]^{2+}$ & $+2 \mathrm{OH}^{-}$ & $\frac{\text { Effect on } \mathrm{pH}}{\text { Increase }}$ \\
\hline (b) $\mathrm{OH}^{-}+$ & $\mathrm{HCl}$ & $=\mathrm{H}_{2} \mathrm{O}$ & $+\mathrm{Cl}^{-}$ & Decrease \\
\hline (c) DT & $+\mathrm{Cu}(\mathrm{II})$ & $=[\mathrm{DT}-\mathrm{Cu}]^{2+}$ & & No change \\
\hline (d) $\mathrm{Cu}$ (II) & $+\mathrm{H}_{2} \mathrm{O}$ & $=[\mathrm{Cu}(\mathrm{OH})]^{+}$ & $+\mathrm{H}^{+}$ & Decrease \\
\hline (e) ([DT & ]$^{2+\ldots 2 \mathrm{OH}}$ & $\begin{array}{l}{[\mathrm{Cr}(\mathrm{VI})]^{2-}=} \\
\text { age })\end{array}$ & $\left.\mathrm{TH}_{2}\right]^{2+\ldots \mathrm{Cr}(\mathrm{VI}))}$ & $\begin{array}{l}+2 \mathrm{OH}^{-} \\
\text {Increase }\end{array}$ \\
\hline
\end{tabular}

At mildly alkaline $\mathrm{pH} \mathrm{Cu}$ (II) forms a Lewis acid-base complex with DT. At lower $\mathrm{pH}$ the Bronsted acidity of $\mathrm{HCl}$ is significantly greater than the Lewis acidity of $\mathrm{Cu}$ (II) and, therefore $\mathrm{Cu}$ (II) ion is displaced from the complex. This is verified by the loss of absorbance at the lower $\mathrm{pH}$. Thus, cationic heavy metals can be adsorbed and desorbed as a function of solution $\mathrm{pH}$. The absorbance ratio at $626 \mathrm{~nm}$ goes through a maximum between $\mathrm{pH} 7.4-7.7$. The lower absorbance ratio at $\mathrm{pH}$ higher than the $\mathrm{pKa}$ is due to the formation of $[\mathrm{Cu}(\mathrm{OH})]^{+}$( reaction (d)) which can be expected to lower the stability of Cu-DT complex and its molar absorbance. Note that the absorbance maximum for the $\mathrm{Cu}$ (II)-DT complex occurs around $\mathrm{pH} 7.5$ which is the mean $\mathrm{pKa}$ of DT. Further, DT can also act as a strong anion exchanger at low $\mathrm{pH}$ when the amine groups are 
fully protonated (reaction (e)) and the anionic heavy metals can be displaced at higher $\mathrm{pH}$ as DT becomes uncharged. The paraffinic chains of DT can act as "sinks" for toxic organics in wastewaters, thus defining the central role of DT in our wastewater treatment scheme. The molecular architecture and a pictorial representation of the mechanism of adsorption/desorption of heavy metals from aqueous solutions are shown in Fig. 3.

\section{B . Preparation of DT-modified Smectites:}

DT can be immobilized at the clay-water interface through favorable electrostatic interactions between the negatively-charged surface sites of smectites and the positively-charged amine groups on DT as shown in Figs. 3B. The stability of the adsorbed layer is further enhanced due to the cooperative interaction between the paraffinic chains of neighboring DT molecules on smectite surface. Thirdly, DT is insoluble in water, and this is expected to minimize loss of adsorbed DT in wastewater streams not containing very high levels of dissolved organics. The more basic amino groups of DT (secondary) are protonated both at low and mildly alkaline $\mathrm{pH}$ and these amino groups will bind strongly to the negative sites of a smectite, both in the interlayer space and on the external surface. Adsorption of DT can be expected to continue beyond the charge equivalence point due to the cohesive interactions between the neighboring paraffinic chains of adsorbed DT and this will impart a net positive charge to DT-modified clay surface. This immobilization scheme is designated as the direct attachment method (DAM). At pH below 3.0, (as shown in Fig. 3B) cationic metal ions will be excluded from the surface and at slightly alkaline $\mathrm{pH}$ the metal ions will be adsorbed at the interface via specific interactions with primary and secondary amino groups. The anionic heavy metals, on the other hand, will be bound to the surface at low $\mathrm{pH}$ as counter ions and will desorb from the surface at higher $\mathrm{pH}$. Thus, a shift in the $\mathrm{pH}$ of the solution can be used to reversibly adsorb and desorb cationic and anionic heavy metals. Alternatively, the smectite surface can be hydrophobed through the adsorption of a monolayer of a strongly cationic quaternary ammonium surfactant such as cetyl benzyl dimethyl ammonium ion (CBDA). Previous work by the Co-PI and his colleagues has shown that CBDA forms an "irreversibly" adsorbed monolayer on smectites such as montmorillonite and hectorite. In a second step, DT is anchored to CBDA-coated clay through hydrophobic interactions to form a mixed bilayer of CBDA and DT. 
This scheme, designated as the hydrophobic attachment method (HAM), is shown in Fig. 3C. This second method can be applied to any detergent molecule containing either an ionic or a nonionic headgroup so long as the hydrocarbon chain on the detergent molecule is long enough to provide strong cohesive interaction with the paraffinic chains of CBDA in an aqueous medium. In fact, we have immobilized palmitic acid (PA; a long chain anionic detergent molecule, insoluble in water) to smectite-CBDA monolayer to yield a smectite-CBDA-PA complex. Adsorption and desorption of cationic and anionic heavy metals can be effected through a switch of the solution $\mathrm{pH}$ as described above. Specifically, we have prepared montmorillonite-DT (MONT-DT), hectorite-CBDA-DT (Hec-CBDA-DT) and hectorite-CBDA-PA by the direct and the hydrophobic attachment methods respectively.

\section{Characterization and properties of modified-smectites:}

The details of the experimental procedures and the characterization techniques have been described in the past technical progress reports. The surface properties of the three smectitesurfactant complexes were measured by (a) organic CHN analysis, (b) Ninhydrin analysis for primary amino groups, and (c) $\mathrm{pH}$ and ESA titrations of modified-clay complexes and these are given in Table 1.

Table 1 Properties of modified-clay complexes:

Clay Complex $\quad$ Method of Preparation Organic Carbon (wt $\%)^{\bullet}$ mmoles DT or PA/g

$\begin{array}{lllll}\text { Hec-CBDA-DT (HCDT) } & \text { HAM } & 38.9 & (47.2 \%) & 0.97 \text { (DT) } \\ \text { MONT-DT } & \text { DAM } & 41.6 & (51.0 \%) & 1.44 \text { (DT) } \\ \text { Hec-CBDA-PA (HCPA) } & \text { HAM } & 28.8 & (38.1 \%) & 0.56 \text { (PA) }\end{array}$

- The organic carbon contents of CBDA, DT and PA are 83.3, 82.5, and 74.9\% respectively. The moles of DT in Hec-CBDA-DT and PA in Hec-CBDA-PA were calculated from the excess organic carbon after subtracting the organic carbon content due to CBDA. The values in parentheses are the weight percent of surfactant coating. The molar ratio of DT/CBDA in Hec-CBDA-DT is 1.2. In the case of MONT-DT, the moles of DT are 3 times the CEC of the base clay. Therefore, 2/3 of 
the adsorbed DT on MONT-DT has formed an insoluble, external surface coating on the base clay. This has since been verified by leaching experiments. With Hec-CBDA-DT and Hec-CBDA-PA, all of adsorbed DT or PA also appear to have formed an insoluble external surface coating.

The results of a $\mathrm{pH}$ and electrokinetic sonic amplitude (ESA) titration of Hec-CBDADT(HCDT) are shown in Figs. 4A and 4B.

Fig. 4A pH Titration and ESA Measurements on HCDT

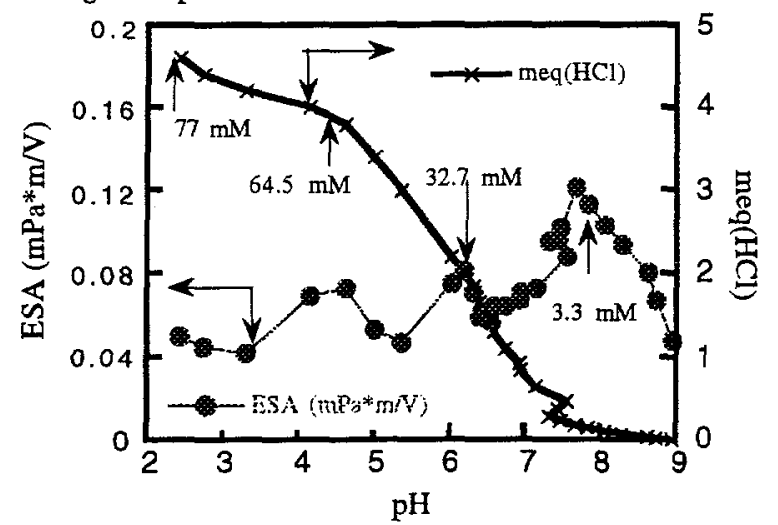

Fig. $4 \mathrm{~B}$ pH Titration of HCDT: Phase Angle vs pH

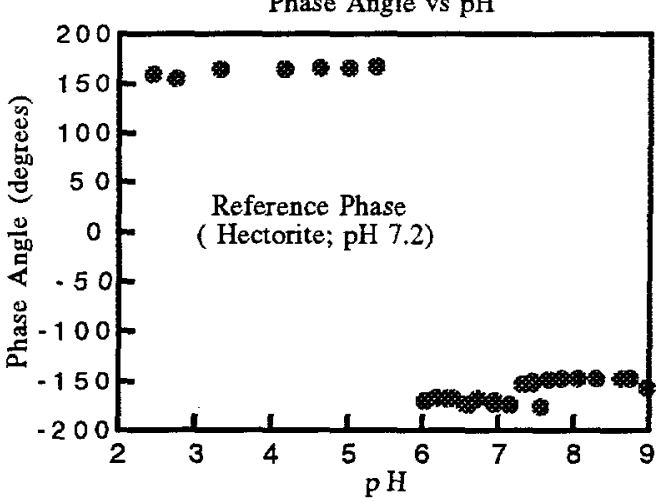

Electro kinetic sonic amplitude (ESA) measurement is a recent technique that has been used to quantify surface charge characteristics of mineral oxides and clay complexes $(17,18)$. ESA measurement was undertaken to correlate potentiometric studies on DT in solution (described above) to the surface properties of clay-DT complexes. Electrokinetic sonic amplitude (ESA) is a complex quantity that represents the magnitude and the phase of the macroscopic pressure wave induced in a suspension of charged colloidal particles when subjected to an oscillatory electric field. The differential acceleration of the particle dipoles relative to solvent molecules produces a net momentum flux on a pair of electrodes placed in the suspension. The theory and the measurement of ESA have been reviewed extensively (18). The observed ESA signal is given by:

$$
\operatorname{ESA}(\omega)=\mathrm{P} / \mathrm{E}=(\mathrm{c})(\Delta \rho)(\phi)\left(\mathrm{G}_{\mathrm{f}}\right)\left(\mu_{\mathrm{d}}\right)
$$

$\mathrm{P}: \quad$ pressure amplitude of sound wave $(\mathrm{mPa})$

E: amplitude of applied field gradient $(\mathrm{V} / \mathrm{m})$

c: velocity of sound in the medium $(\mathrm{m} / \mathrm{s})$

$\Delta \rho:$ density difference between the particle and the continuous phase $(\mathrm{kg} / \mathrm{m} 3)$ 
$\phi: \quad$ volume fraction of the solids (dimensionless)

$\mathrm{G}_{\mathrm{f}}$ : electrode geometrical factor (dimensionless)

$\mu_{\mathrm{d}}:$ frequency dependent electrophoretic mobility (m2/sec/V)

$\omega:$ frequency of the applied ac field.

Eq. 1 is valid in the " linear " regime of particle volume fraction ( 0.05 or less) and is applicable to our experiments reported here that have been carried out at a volume fraction of 0.013 . The ESA as given by the left hand side of Eq. 1 is a measurable quantity and can be separated into magnitude (modulus) and phase angle components. The latter refers to the "lag" in the ESA signal relative to the signal of a reference material of the same polarity (i.e. having the same sign of surface charge). Since the phase angle changes sharply at the onset of charge reversal, any change in the sign of surface charge during acid-base titration can be located more precisely using the phase angle component than the modulus of ESA. Thus, the modulus of observed ESA signal was used as an indicator of the magnitude of the surface charge, and the phase angle its sign.

2 gms of HCDT were conditioned in DI water for 36 hours with initial sonication for 15 minutes and continuous mixing thereafter. The suspension was titrated with $2 \mathrm{M} \mathrm{HCl}$ ( as was done with DT in solution ) and the ESA signal, the $\mathrm{pH}$ and the temperature of the suspension were measured after each acid addition. Blank ESA titrations with increasing concentrations of $\mathrm{NaCl}$ were also carried out to correct for the contribution of the indifferent electrolyte to the ESA signal. The following points can be made from Figs 4A and 4B.

(1)The addition of $\mathrm{H}^{+}$ions to HCDT suspension produces a titration curve similar to the one observed in the solution of DT. However, the apparent mean pKa of the adsorbed DT ( Fig. 4A) is 7.0 because, the more basic of the DT molecules will have reacted with the negative sites on hectorite. (2) The ESA signal ( Fig. 4A) is of very low magnitude, but positive over the entire $\mathrm{pH}$ range of the titration. This suggests superequivalent adsorption of the surfactant leading to positive surface charge on the modified-smectite surface. (3) The above assertion is verified by the phase angle data (Fig. 4B ) which show that the phase of the observed ESA signal is shifted by 180 degrees with reference to the ESA signal of unmodified smectite (hectorite) which is negatively 
charged over the $\mathrm{pH}$ range studied. (4) The equivalence point of acid titration ( Fig. 4A) yields a value of $1.02 \mathrm{mmoles}$ DT/g HCDT which is close to the value of 0.97 mmoles DT /g HCDT measured by organic carbon and Ninhydrin assay methods. (Note DT takes up 2 moles $\mathrm{HCl} / \mathrm{mole}$ ). (5) The ESA signal increases as $\mathrm{HCl}$ is added to the suspension indicating protonation of surface diamine groups. However, the ESA signal decreases at even lower $\mathrm{pH}$ and shows oscillations. The following is the explanation for the observed behavior of the ESA signal. Titration of $\mathrm{HCl}$ into HCDT suspension adds $\mathrm{Cl}^{-}$ions to the suspension and it is known that the ESA signal of the background electrolyte such as $\mathrm{NaCl}$ can be $30-50 \%$ of the ESA signal of HCDT, but opposite in polarity. The various concentrations of the chloride ion during titration ( ranging from 0-77 $\mathrm{mM}$ ) are shown in Fig. 4A. The oscillation in the ESA signal is perhaps due to the low magnitude of signal itself.

\section{Adsorption/desorption of Heavy metals:}

The $\mathrm{pH}$ dependence of uptake and release of $\mathrm{Cu}(\mathrm{II}), \mathrm{Cd}(\mathrm{II})$, and $\mathrm{Cr}(\mathrm{VI})$ from HCDT, HCPA, and MONT-DT respectively is shown in Figs. 5A-5C. In Fig. 6 is shown the adsorption of $\mathrm{Cu}$ (II) onto HCDT at pH 7.2 and 3.0. It can be seen from Figs. 5A - 5C (for which the data were obtained at a fixed initial metal ion concentration ) that both cationic and anionic heavy metals have a sharp $\mathrm{pH}$ dependent adsorption/desorption characteristics. For example, with $\mathrm{Cu}(\mathrm{II})$ ions adsorption onto HCDT is zero at $\mathrm{pH} 4.5$ and quite high above $\mathrm{pH}$ 7.2. On the other hand, $\mathrm{Cr}(\mathrm{VI})$ uptake exhibits, not unexpectedly, an opposite $\mathrm{pH}$ trend, adsorbing at low $\mathrm{pH}$ and desorbing at high $\mathrm{pH}$. It should be noted all the data were obtained in buffered media at an ambient ionic strength of $20 \mathrm{mM}$. In the case of $\mathrm{Cu}$ (II), full isotherms of adsorption at the two $\mathrm{pH}$ extrema ( $\mathrm{pH} 3.0$ and 7.2) were measured and the results shown in Fig. 6 reveal a Langmuir type adsorption at pH 7.2 and very little or no uptake at $\mathrm{pH}$ 3.0. The selectivity ratio (defined as the ratio of the affinity constants at the two $\mathrm{pH}$ ) was found to be 773 in favor of the higher $\mathrm{pH}$. A limiting adsorption capacity of 0.34 mmole $\mathrm{Cu}(\mathrm{II}) / \mathrm{g}$ HCDT at $\mathrm{pH} 7.2$ was obtained. It was observed that total release of adsorbed $\mathrm{Cu}$ (II) ions could be effected by lowering the $\mathrm{pH}$ to 3.0 after initial adsorption at the higher $\mathrm{pH}$. 
Fig. 5A. Adsorption/desorption of $\mathrm{Cu}(\mathrm{II})$ on HCDT:

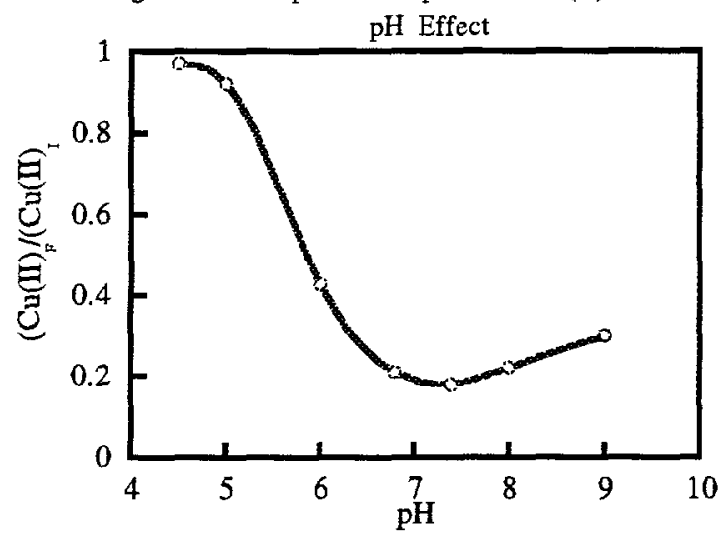

Fig. 5C. Adsorption/desorption of $\mathrm{Cr}$ (VI) on MONT-DT: $\mathrm{pH}$ Effect

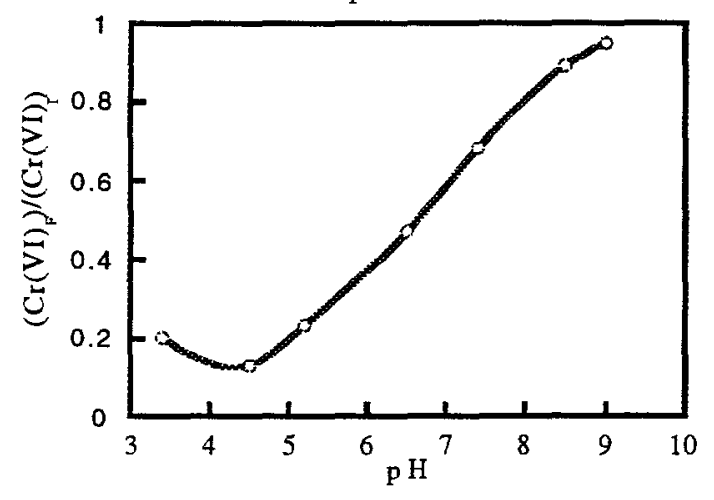

Fig. 5B. Adsorption/desorption of Cd(II) ions on HCPA: $\mathrm{pH}$ Effect

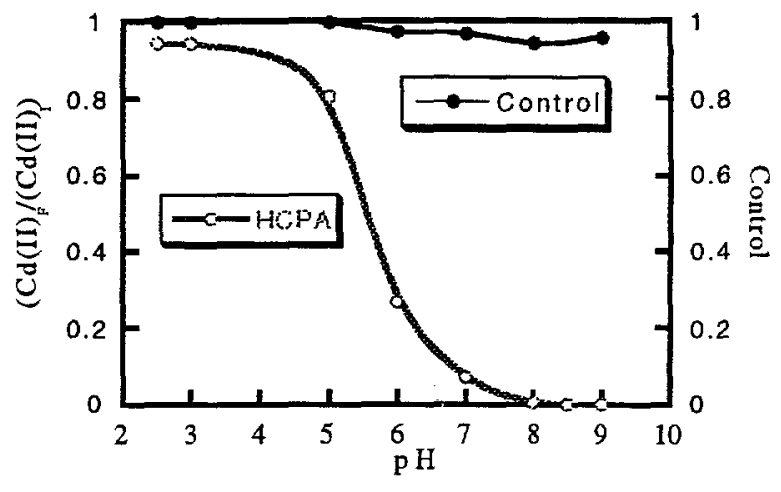

Fig. 6 Adsorption of $\mathrm{Cu}$ (II) onto HCDT

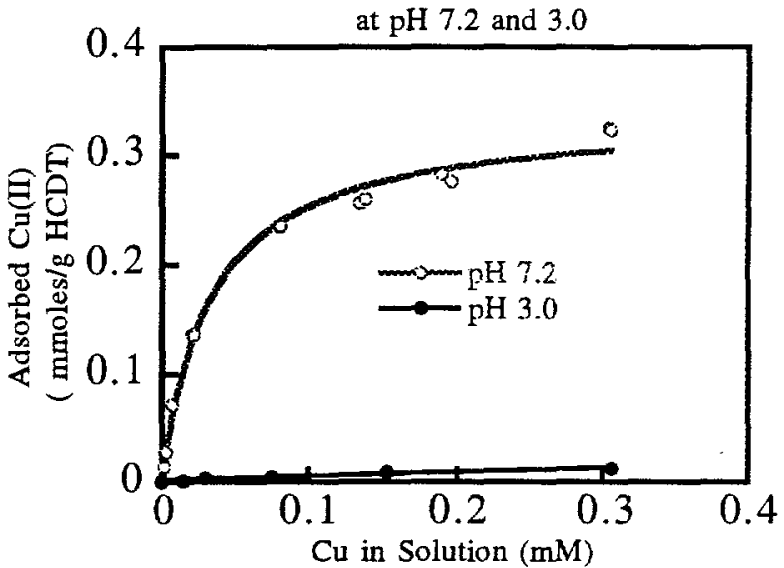

Similar uptake/release experiments with $\mathrm{Cr}(\mathrm{VI})$ and $\mathrm{Cd}(\mathrm{II})$ have also been undertaken with identical results. Further, MONT-DT and HCDT have been found to be equivalent in many of their heavy metal ion adsorption/desorption characteristics. Finally, experiments at higher ionic strength reveal that $\mathrm{Cu}(\mathrm{II})$ adsorption by HCDT and MONT-DT involves acid-base interaction while $\mathrm{Cr}$ (VI) binds to the same modified-clay surfaces via anion exchange.

\section{E. Sorption of Toxic Organics:}


Sorption of ionogenic organic compounds, 3,5-dichlorophenol (DCP), 2,4,5-trichlorophenol (TCP), $\beta$-naphthoic acid and a PAH, phenanthrene, onto HCDT and MONT-DT have been examined. The results are discussed in Table 2 .

Table 2. Sorption of Toxic Organics.

DCP

TCP

\section{Phenanthrene}

Sorption $\mathrm{pH}$ dependent; Langmuirian in shape. Limiting adsorption density levels off above $\mathrm{pH}$ 7.0. Presence of $\mathrm{Cu}(\mathrm{II})$ ions in solution has an inhibitory effect possibly through $\mathrm{Cu}(\mathrm{II})-\mathrm{DCP}$ complexation in solution. Sorption is also $\mathrm{pH}$ dependent, more pronounced than in the case of DCP. $\mathrm{Cu}$ (II) ions in solution inhibit uptake. This is shown in Fig. 7 below.

$\beta$-naphthoic acid. With a pKa of $4.17, \beta$-naphthoic acid binds mostly as an anion in the $\mathrm{pH}$ range $4.0-7.0$. The adsorption is inhibited by the presence of $\mathrm{Cr}(\mathrm{VI})$ in solution. Other adsorption mechanisms such as nonpolar interactions and H-bonding appear to be responsible for measurable uptake at $\mathrm{pH} 9.0$. A linear and high affinity partitioning behavior typical of a hydrophobic organic compound (HOC).

Fig. 7 Adsorption of TCP on HCDT at pH 7.0:

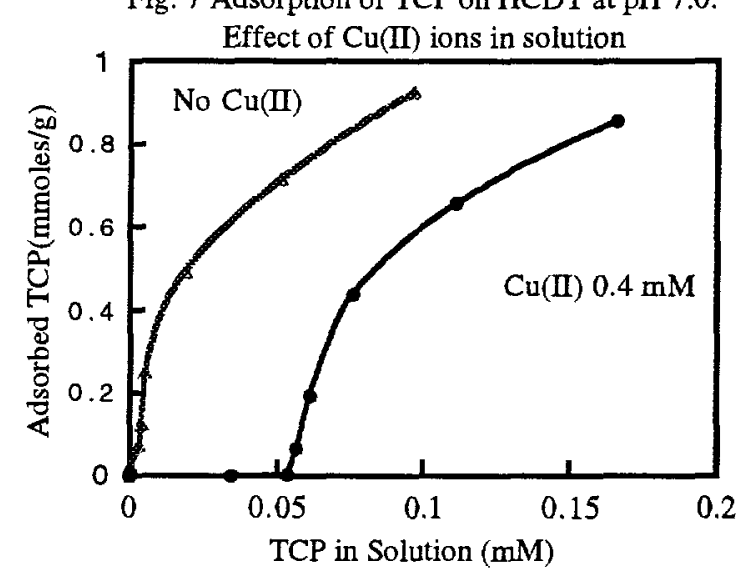




\section{F. Multi-step Adsorption/Desorption of $\mathrm{Cu}$ (II) onto HCDT and The Stability of}

Adsorbed DT:

Application of surfactant-modified clays developed by us for the removal and recovery of heavy metals from wastewaters requires that the adsorbent be used and re-used many times without any loss of sorption affinity or capacity. Such re-use will greatly enhance the cost effectiveness of modified-clay adsorbents in field applications.

A $5 \mathrm{mg} / \mathrm{ml}$ suspension of HCDT was suspended and sonicated in a pH 7.2 aqueous solution containing $20 \mathrm{mM} \mathrm{NaCl}$. pH was adjusted using $\mathrm{HCl}$ and $\mathrm{NaOH}$ solutions. Suspensions of $\mathrm{HCDT}$ ( $10 \mathrm{ml}$ total volume containing $20 \mathrm{mg} \mathrm{HCDT}$ ) were mixed with an initial $\mathrm{Cu}$ (II) concentration of $20 \mathrm{ppm}(0.32 \mathrm{mM})$. After $2 \mathrm{hrs}$ of adsorption, clay was separated by centrifugation and the entire supernatant solution was carefully removed for $\mathrm{Cu}$ (II) assay by atomic absorbance spectroscopy (AAS). Desorption of adsorbed Cu(II) was carried out by contacting the sedimented HCDT with a pH 3.0 solution at the same ionic strength. Desorption was allowed to proceed for 2 hours and the solid/liquid separation was effected once more by centrifugation. The desorption supernatant was withdrawn and analyzed for $\mathrm{Cu}(\mathrm{II})$ by $\mathrm{AAS}$. The above step of adsorption and desorption was repeated by re-suspending the sedimented HCDT in fresh $\mathrm{pH} 7.4$ solution and re-adjusting the $\mathrm{pH}$ with very small volumes of concentrated $\mathrm{HCl}$ or $\mathrm{NaOH}$. A fresh aliquot of $\mathrm{Cu}$ (II) solution was added and the process of adsorption and desorption continued. The results are shown in Figs 8 and 9. As shown in Fig. 8, during the first adsorption step at $\mathrm{pH} 7.4, \mathrm{Cu}(\mathrm{II})$ ions adsorb very strongly strongly to HCDT and more than $95 \%$ of the $\mathrm{Cu}(\mathrm{II})$ initially added is bound to HCDT. The bound $\mathrm{Cu}(\mathrm{II})$ ions are quantitatively desorbed during the first desorption step. Subsequent adsorption desorption steps ( steps 2 - 5, as shown in Fig. 8) the efficiency of $\mathrm{Cu}$ (II) uptake is lowered by less than $5 \%$. Control experiments with $\mathrm{Cu}$ (II) ions at the identical initial concentration ( $20 \mathrm{ppm} ; 0.32 \mathrm{mM}$ ) show no loss of $\mathrm{Cu}(\mathrm{II})$ ions from solution by precipitation or nonspecific adsorption. The overall mass balance for the multi-step experiment is depicted in Fig. 9. It can be seen that mass balance ranges from $92-102 \%$ with a mean mass balance of $97 \%$. The data 

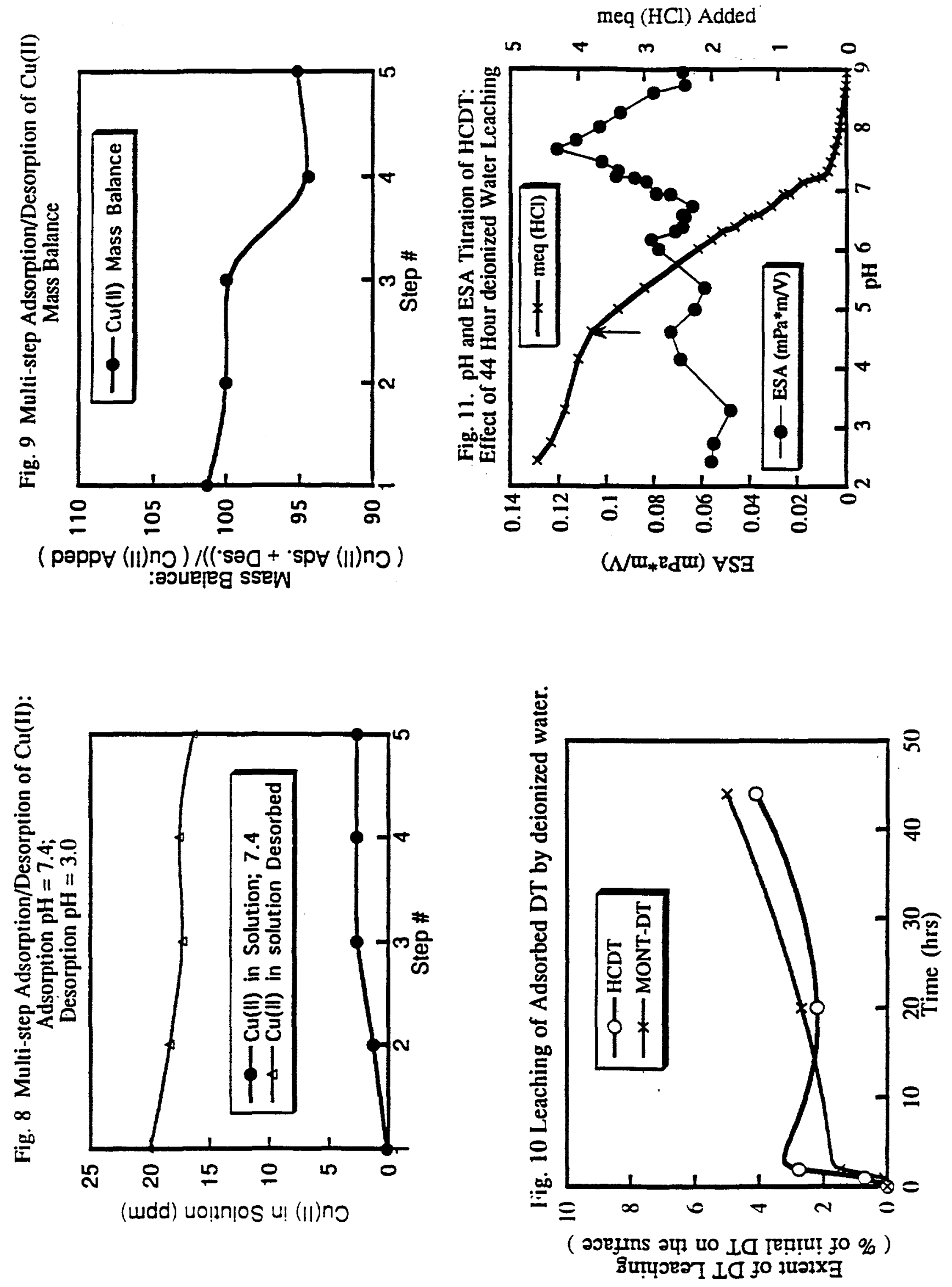
presented in Figs 8 and 9, taken together, show that HCDT can be used at least five times to remove and recover $\mathrm{Cu}$ (II) ions from aqueous solutions.

The stability of DT on HCDT and MONT-DT was monitored by continuous leaching of HCDT with deionized water. DT released into the leaching solution was assayed by the Ninhydrin method and the results are shown in Fig. 10. It can be seen that DT bound to HCDT or MONT-DT is mobilized to the extent of less than $6 \%$ after $44 \mathrm{hrs}$ in aqueous medium. Thus, the small loss of potency of HCDT for $\mathrm{Cu}$ (II) uptake during repeated adsorption/desorption cycle ( see Fig. 8) is attributed partly to the loss of DT from the surface and partly to the incomplete washing of the adsorbent between each adsorption/desorption step. Similar tests were carried out on MONT-DT as well with nearly identical results. In order to verify the above results of leaching experiments, $\mathrm{pH}$ titration and electrokinetic measurements on HCDT and MONT-DT were carried out as a function of leaching time. Continuous leaching of HCDT and MONT-DT in deionized water was carried out upto $44 \mathrm{hrs}$ and the samples were periodically subjected to simultaneous $\mathrm{pH}$ and ESA titrations.

\section{Publications and Presentations:}

(1) Keeran R. Srinivasan and Henry Y. Wang: Proceedings of the Joint Symposium on Environmental Engineering by Canadian and American Societies of Civil Engineering Montreal, Quebec, Vol. II, 1111, (1993).

(2) Keeran R. Srinivasan and Henry Y. Wang: A paper presented at a Symposium on "Clays in Environment" at The Annual Clay Minerals Society Meeting, San Diego, CA, Sept. 1993.

(3) Lin, J. E., Hickey, R.F., Shen, G.J., and Wang, H.Y. : " Biotechnology Applications in Hazardous Waste Treatment " Ed. G. Lewandowski, 1990.

(4) Srinivasan, Keeran, R. and Fogler, H. Scott: Clays \& Clay Minerals , 38, 287 (1990).

(5) Keeran R. Srinivasan, Morton, John, F., and Hayes, Kim, F.:: Proceedings of the Joint Symposium on Environmental Engineering by Canadian and American Societies of Civil Engineering, Montreal, Quebec, Vol. II, 1335, (1993).

(6) Siahpush, A. R., Lin, J.R., and Wang, H.Y.: " Adsorbent Design in Co-Immobilized Systems for Degradation of Toxic Organics "Biotechnol. Bioeng. 39:619-628, 1992. 


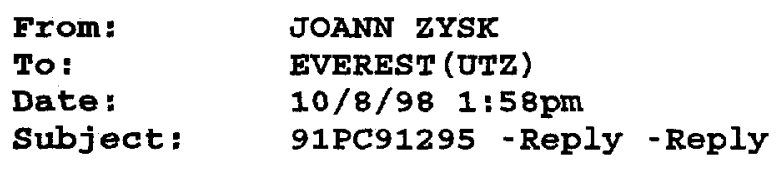

Yes, PADS does show steve. The organization is university of Michigan and the Final Report is entitled: "An Integrated system for the Treatment of Coal Conversion Wastewaters." It isn't very long - $13 / 14$ pages.

$\gg>$ BRUCE UTZ 10/08/98 12:50pm $\gg>$

Joann, Provide me with the name of the organization, and I will check. I assume that PADS is showing steve Bossart?

\section{Bruce}

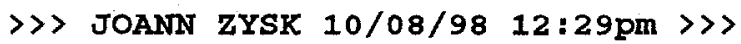

Bruce:

Could you assist me or send me in the right direction? I have a final report to send to a COR for review and approval. Unfortunately, this is in closeout and the last cor identified is steve Bossart. However, he said that he is not the COR. Where do I go from here? 